\title{
A Multi-Robot Formation Control System Design
}

\author{
Jiansheng Peng ${ }^{*}$ \\ Department of Physics and Mechanical \& Electronic Engineering, Hechi University, Yizhou 546300, China
}

\begin{abstract}
In order to realize the formation of multi-robot control. We uses RFID radio frequency card positioning method and the formation of a ZigBee network with combining sensors, we establish data center to control the formation of four robots. Data center takes STM32 as master, and CC2530 is as a communications platform, each robot is controlled by STM32 master, CC2530 wireless communication module, compass module, RFID reader modules and other components. Experimental results show that this method can effectively, accurately and quickly control multiple robots formation.
\end{abstract}

Keyword: Multi-robot, wireless sensor networks, formation Control.

\section{INTRODUCTION}

Throughout the ideas of Formation Controls, we can think of nature group activities. When an animal is attacked, it will immediately form a specific formation to resist attack; the hunting party is put on the team's formation in order to better combat to defeat opponents, unity is strength, give full play to the advantages of an individual. So for robot systems, multi-robot to maintain a specific formation will have the following mechanical and electrical advantages: 1) the surroundings of each robot may be not the same and the limited capacity of each robot cannot perceive the whole environment and systematic. If the division of labor between the robot and share the surroundings, so that the system can quickly make the right response to external interference. 2) The formation of multi-robot maintains a specific attack on the outside can enhance defense capabilities. 3) In particular task, to maintain a specific formation can be more effective. 4) Can improve the robustness of the system [1-5]. As technology advances and technology, so that the processing speed, processing power robot perception of things growing, increasingly demanding, from the research phase into the natural environment of the laboratory to form a very good robot formation control platform. The United States took the lead on multi-robot studied Georgia TechMobile Robot Lab combines the DARPA UGV (unmanned ground vehicle) Demo II study the formation control method based on behavior [6]. We should give full play to the role of each robot, the robot must make more than a division of labor, together. Many colleges and universities have carried out research work in this area, and in the theoretical basis of multi-robot collaboration on related research carried out [7-10]. In addition, Shanghai Jiaotong University, HUST and other schools to adopt the United States of SRI Poineer2 / DX systems for learning and development, and an indoor multi-robot

*Address correspondence to this author at the Department of Physics and Mechanical \& Electronic Engineering, Hechi University, Yizhou 546300, China; E-mail: Sheng120410@163.com formation made a significant contribution [11]. American Development CESAR Emperor and CESAR Nomads [12] indoor and outdoor systems, allowing multiple robots collaborate in position against outside interference environment.

\section{SYSTEM DESIGN}

The system hardware platform and the main center of the terminal portion of the robot controlled by a robot composed of mechanical robot comprise a robot, power module, compass module, RFID reader module. Control centers and robots are used to ARM master terminal (STM32F103VCT6) and CC2530 module is mainly controlled robot master performs related operations. Exchange CC2530 module is in charge of data.

System works as follows: the robot is responsible for reading RFID card to determine their location, and then read the compass data is then sent through the CC2530 module, the control center receives these data via the formation control algorithm to generate the appropriate correspondence the directive also sent out by CC2530 module, after receiving the command-driven servo robot forward and back, left and right turn and other sports. By STM32F103VCT6 master control center and CC2530 modules, robot part by the STM32F103VCT6 master, CC2530 module, compass module, RFID reader, servos, etc., the system hardware block diagram shown in Fig. (1).

\subsection{Host Controller Hardware Designs}

System STM32F103VCT6 processor as the main controller chip. This mainly contains two serial communication interfaces, an $\mathrm{I} 2 \mathrm{C}$ data interface, power regulator circuit, and the minimum system control circuit shown in Fig. (2). STM32F103VCT6 12 and 13 pins for the external clock input terminal, C15, C16 values generally between 15PF 30PF, this design uses 22PF, R26 and C5 reset circuit, C17, C7, C18, C19, C20 for decoupling capacitance. 

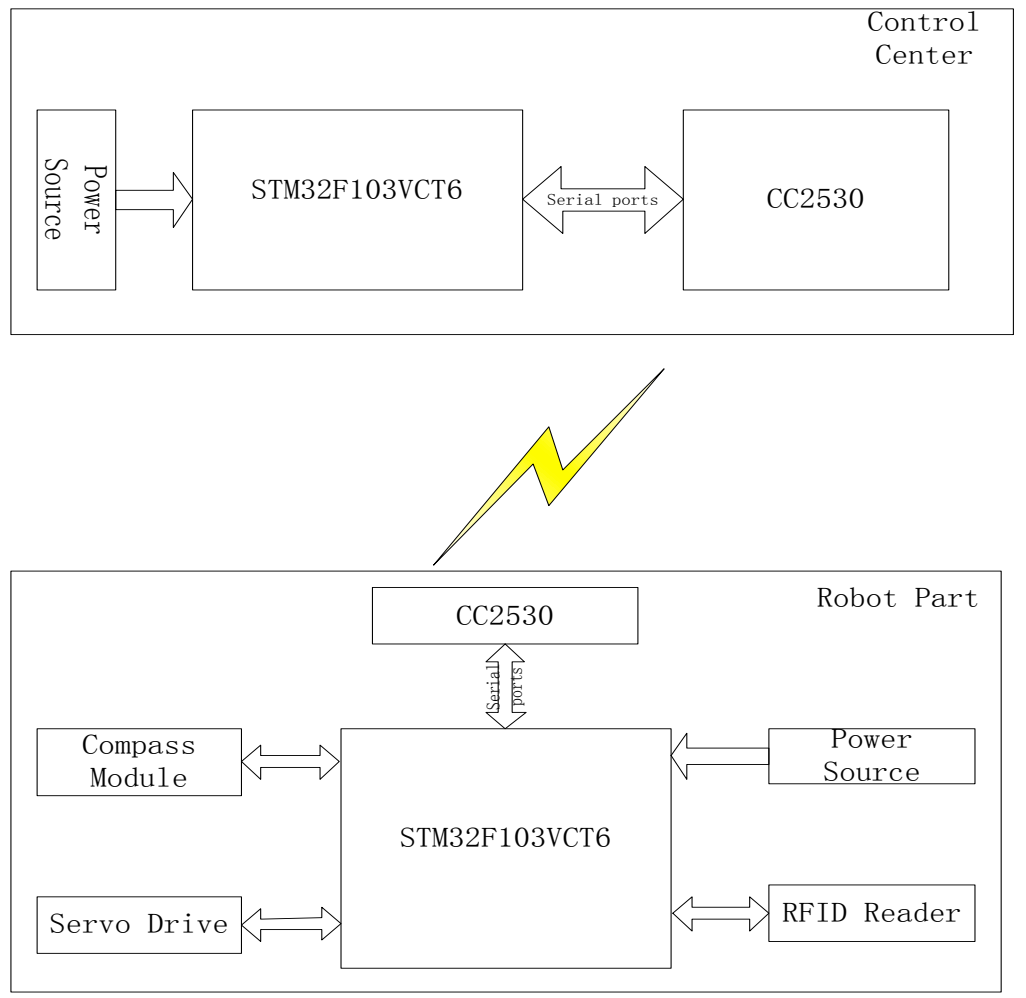

Fig. (1). Block diagrams of the system.

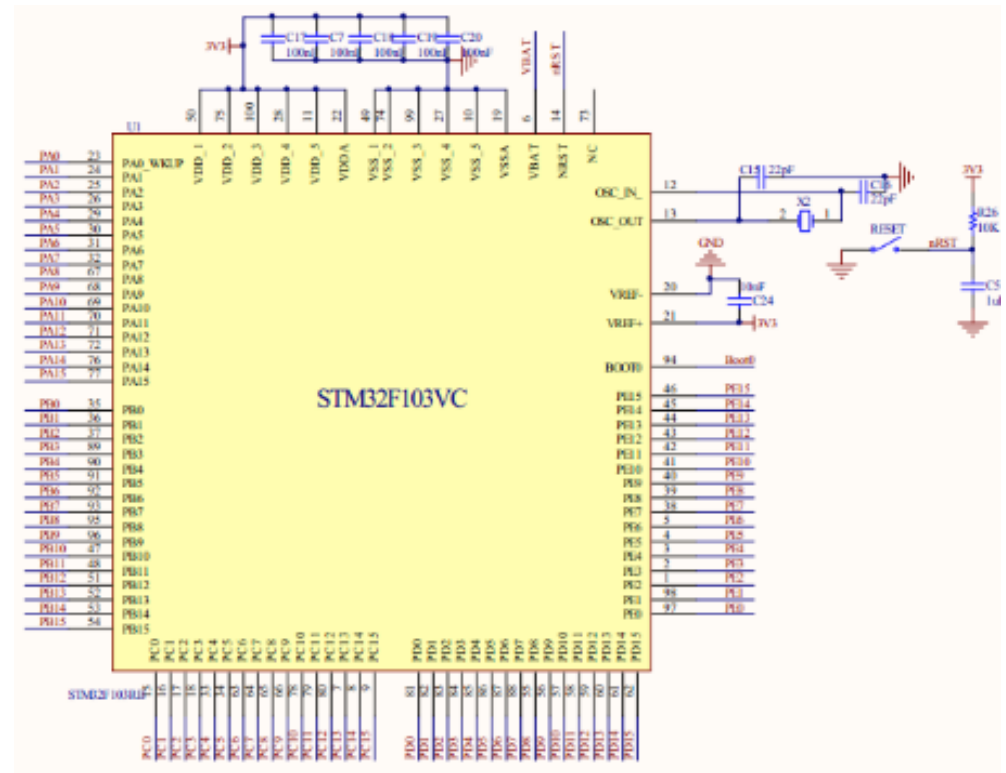

Fig. (2). Master hardware circuit schematics.

\subsection{Wireless Communication Platform Hardware Design}

Hardware design of wireless communication platforms is mainly CC2530 as the core, the circuit diagram shown in Fig. (3). CC2530 integrates very high, so the external circuit is relatively simple, the main attention to issues such as impedance matching and interference design. Download also used JTAG mode, JTAG convenient for 10P double-pin connector emulator download and debug procedures.

\subsection{Compass Module}

The system uses GY-26 compass module for robot navigation. The measurement range is between $0^{\circ}-360^{\circ}$, the resolution can reach $0.1^{\circ}$. VCC modules connect $+5 \mathrm{~V}$. GND connected with the STM32, SDA pin connecting the STM32 PA11, SCL connection PA12. Here's the way to use the software simulation I2C driver. GY-26 Compass Module kind has been shown in Fig. (4). 


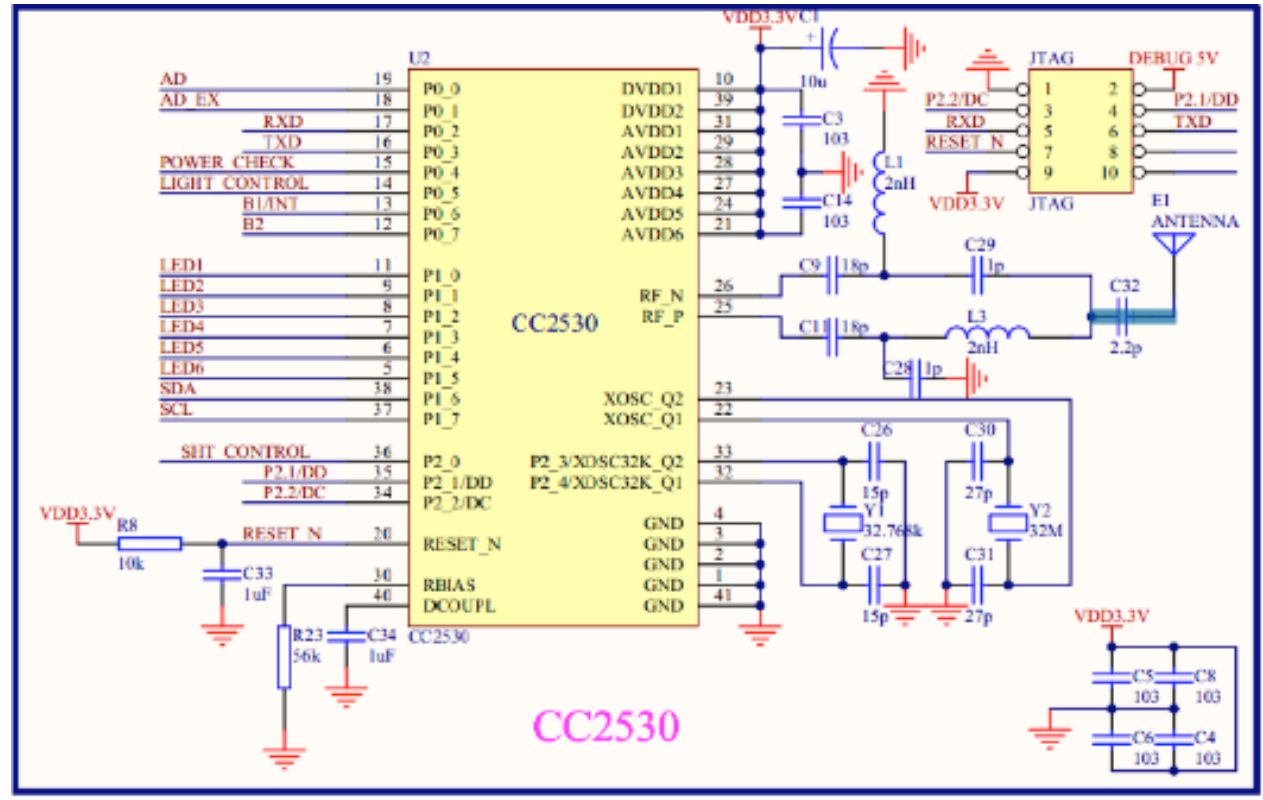

Fig. (3). Wireless communication platform hardware schematics.

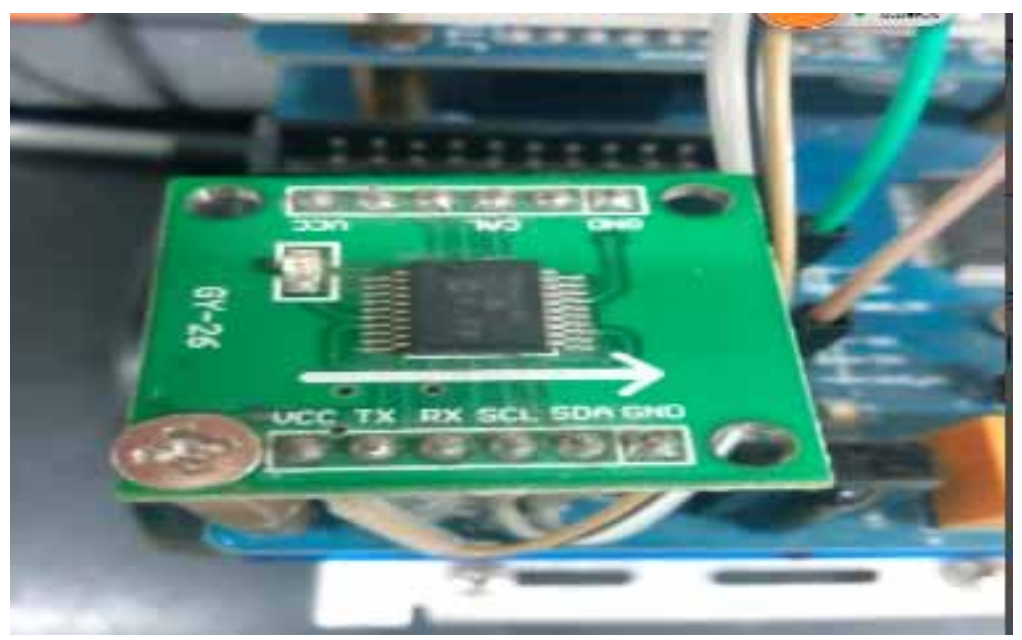

Fig. (4). GY26 physical map compass modules.

\subsection{RFID Reader Module}

RDIF reader is used to read the ID value of RFID tags, which use the serial port directly connected to the STM32 serial port 2 (PA2, PA3), both of which are output TTL level. VCC pin is used to provide power to the RFID reader, / ENABLE pin is used to control the RFID reader startup and shutdown, when the pin is low red, indicating the start of work, when the pin is high level green light, indicating close reader function, SOUT pin is an electronic tag reader ID value distributed interface controller, GND connected to power ground, RFID reader Module kind shown in Fig. (5).

\subsection{Power Modules}

The shown Power in part by $5 \mathrm{~V}, 3.3 \mathrm{~V}$ voltage regulator circuit. Servos, RFID reader, compass requires a 5V supply, while the STM32, CC2530 microprocessor with 3.3V power supply. Fig. (6) is a circuit diagram LM7805 regulator. Vin is $7.4 \mathrm{~V}$ lithium batteries, Vout output is $5 \mathrm{~V}$. Fig. (7) is a LM1117 voltage regulator circuit diagram, D9 is the power indicator, R12 for the current limiting resistor.

\section{ROBOT LOCALIZATION AND FORMATION CONTROL}

\subsection{Establish RFID Data Memory Matrices}

The experimental site is provided into $\mathrm{n}$ rows and $\mathrm{m}$ columns, $\mathrm{n} \times \mathrm{m}$ a common RFID card laying the experimental site. Establishing an array of $\mathrm{n}$ rows and $\mathrm{m}$ columns of $\mathrm{W}$, the $\mathrm{n} \times \mathrm{m}$ array $\mathrm{W}$ stored in an RFID card in. Storage way: RFID card i-th row $\mathrm{j}$-th column of the ID numbers stored in 

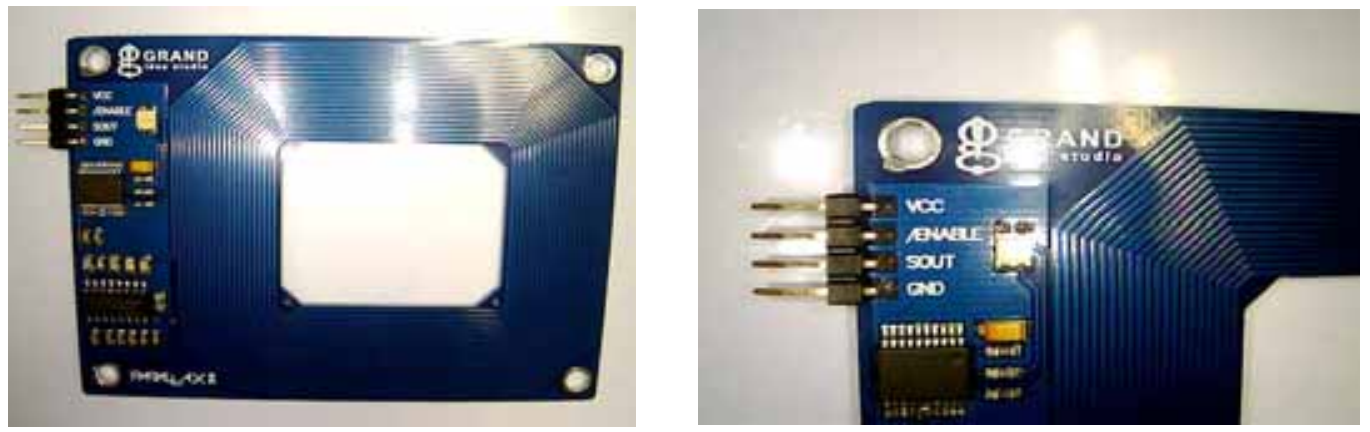

Fig. (5). RFID reader module kinds.

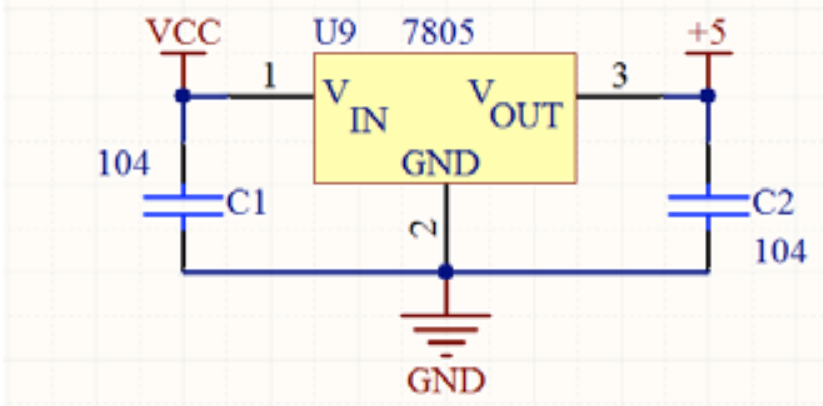

Fig. (6). 5V regulator circuit schematics.

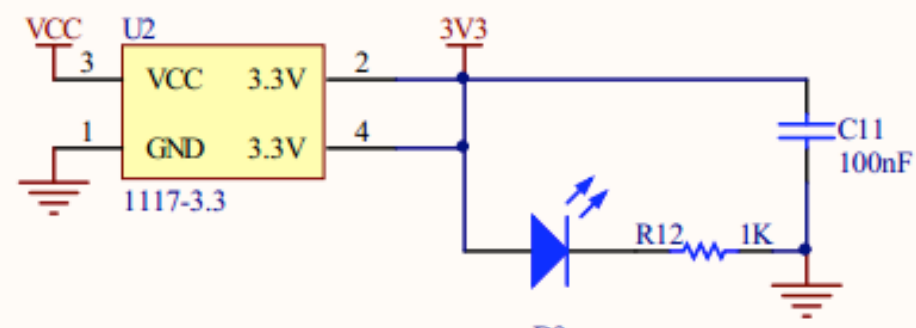

D9

Fig. (7). 3.3V voltage regulator circuit schematics.

the $\mathrm{i}$-th row of the array $\mathrm{W}$ is the $\mathrm{j}$-th column, i.e. RFID card ID number stored in the same row of the array $\mathrm{W}$ of the member. Establishing RFID card ID number storage array W is to facilitate the location of the robot's own query. When the robot reads the current RFID card ID numbers, can be found in the corresponding position information in the array W.

\subsection{RFID Positioning Establishes Mathematical Model}

Since the experimental site is divided into a grid of $n$ rows and $m$ columns, each of the grid has a RFID card, and only one RFID card. Therefore, each RFID card has one and only one position corresponding thereto, in this position may be expressed as $\mathrm{i}$ and the row $\mathrm{j}$ of fuzzy columns, where the number of ranks of the RFID card.

Robot using the RFID reading device is provided current ID number, which is expressed as q. Found with the same ID number by searching the array $\mathrm{W}$, and returns the number of rows of the member $\mathrm{Q}$. When expressed as a mathematical model, as shown in Formula 1.

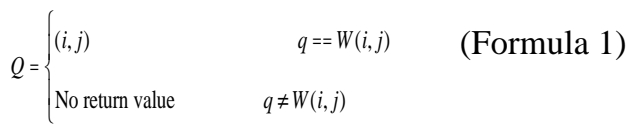

The exact location information can be obtained $Q$ positioning of the robot, the positioning accuracy and the size of the RFID card that is the positioning accuracy of an RFID card side.

\subsection{Robot Formation Control Methods}

Robot according RFID card information and the angle of deflection of the compass may be implemented to control the robot path, the card information that defines the entire experimental site within a two-dimensional array of $30 * 30$, as 


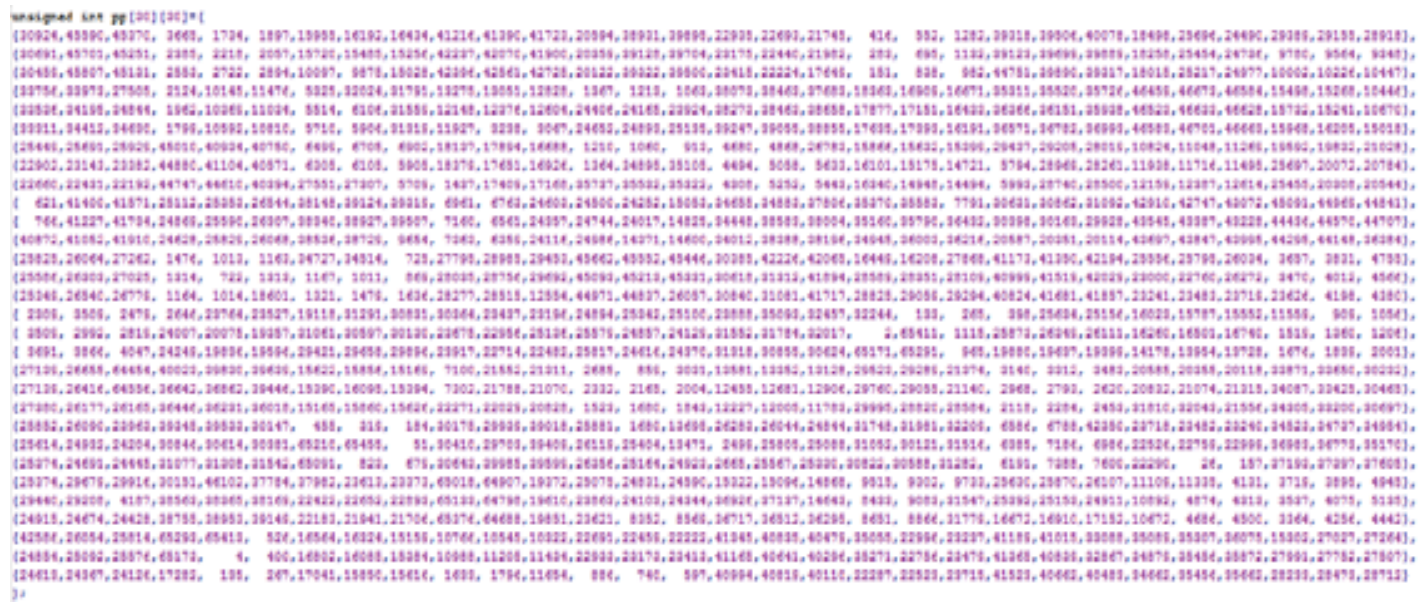

Fig. (8). The actual card number photos.

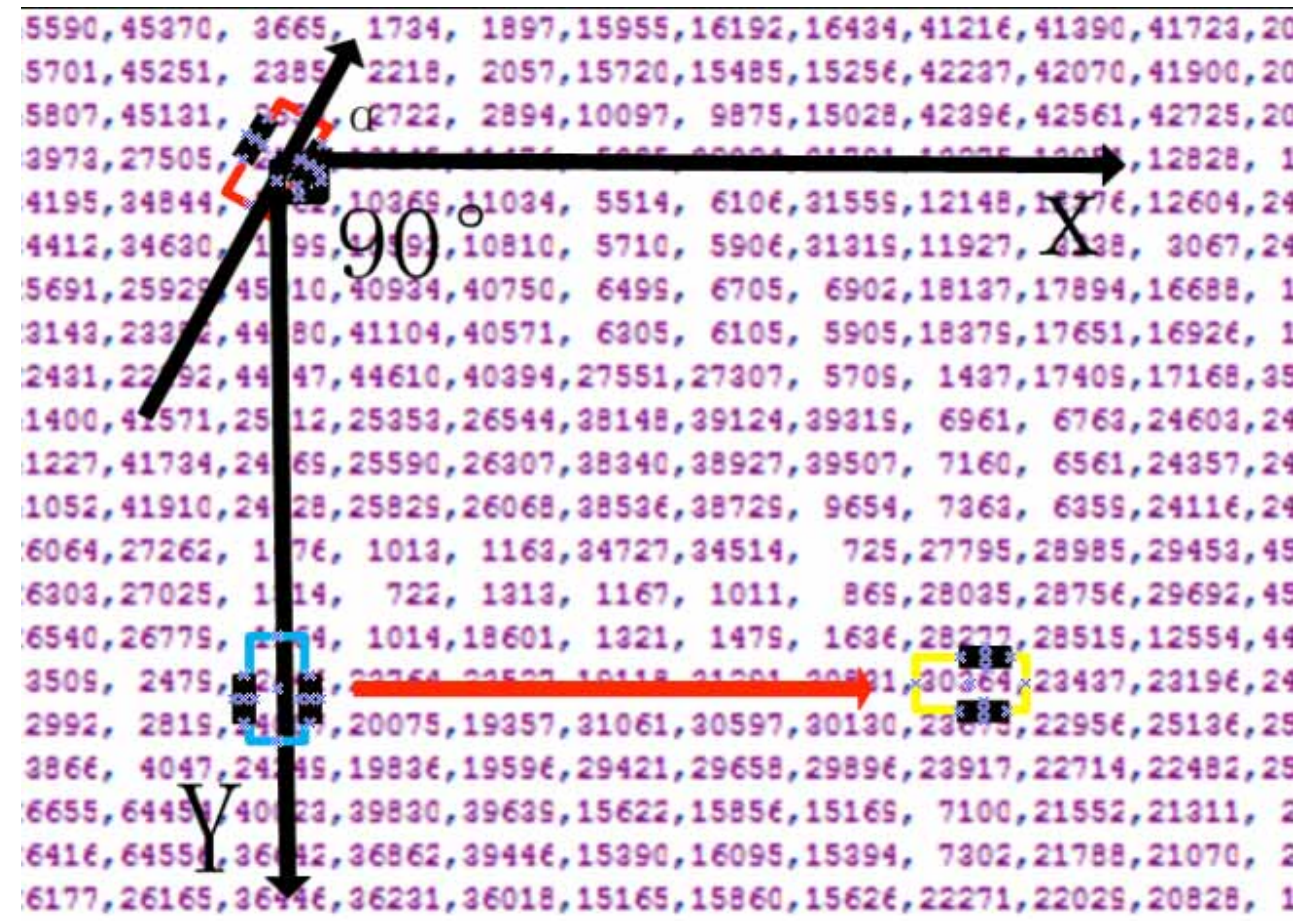

Fig. (9). Schematic diagram of walking robots.

shown in Fig. (8). When the angle between the initial position of the robot in the PP [x0] [y0] red squares shown in Fig. (9), the compass to the robot detects the $\mathrm{X}$-axis is $\alpha^{\circ}$, then to move to the PP [x1] [y1] the position shown in counterclockwise rotation yellow box shown in Fig. (9), you will need to rotate clockwise $\alpha+90^{\circ}$ after the post went straight parallel with the $\mathrm{Y}$-axis position shown in the blue box and then go straight to reach $90^{\circ}$ after 9 yellow the position shown in the box.

\section{SOFTWARE DESIGN}

\subsection{Compass Module Programming}

GY26 serial and I2C provide two communication protocols to connect with the microcontroller, since the STM32 with RFID, STM32 and CC2530 will need a serial connection, serial port resource constraints, so the design uses I2C communication. Program flow chart is shown in Fig. (10).

\subsection{RFID Reader Program Designs}

RFID reader connected through the serial port with STM32, programming began first to configure the communication port, pin operation mode signal port baud rate. When the enabled terminal RFID cards at a high level in the standby mode, when the enable terminal is pulled down into the working mode, then drive the antenna query tab. If RFID card in the antenna area, a unique ID to a 12-byte ASCII string following the way to the STM32, STM32 extract the contents of the string and converted to give the card number. Read the flow chart shown in Fig. (11). 


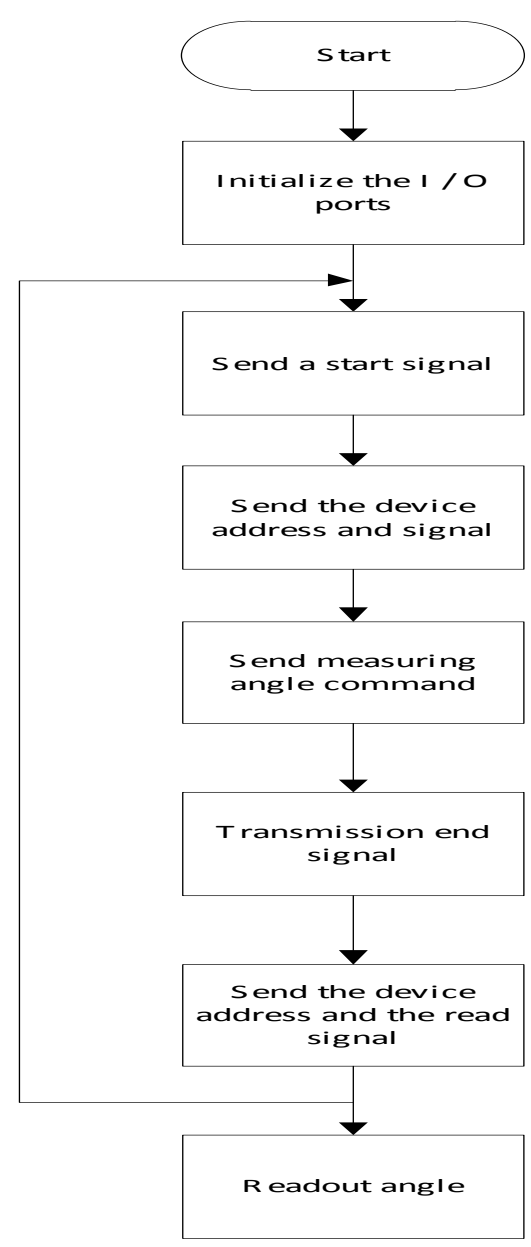

Fig. (10). Compass module program flowchart.

\subsection{Robot Formation Control Program Designs}

Control center receives all the robot coordinate position angle and then compare according to predefined formation, then the output of each robot control commands sent through the wireless, the robot receives the corresponding instruction is executed straight, backward, left and right transfer and other operations. Robot formation control program flow chart is shown in Fig. (12).

\section{TEST RESULTS AND DATA ANALYSIS}

During the commissioning process, from the single robot control and then to multiple robot control, in this process should also consider dropping the case and cannot look at the card. Table 1 corresponds to the table to perform the robot operation instruction A is transmitted by a control center. Control Center now free to send 100 commands to the robot A, then A record number of robots to perform. After the test, the robot can pick the number of the received 98 times. When a single robot under the control packet loss rate is not very high, the impact is not great. Test results show CC2530 module in short distance wireless transmission is relatively stable.

Control methods and objectives: first robot A, B, C, D on a fixed starting point (A: P [0] [1], B: P [0] [10], C: P [0] [20 ], D: after the P [0] [28]), a broadcast control center in the

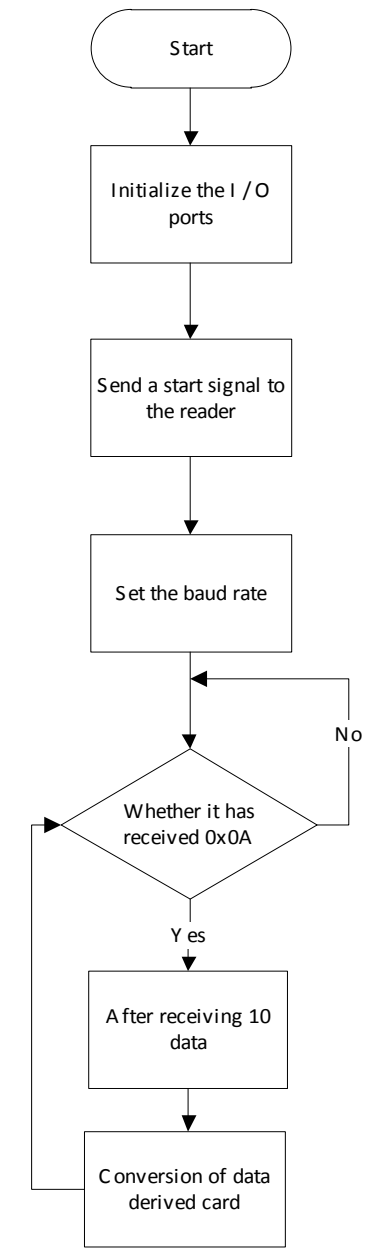

Fig. (11). RFID reader flowchart.

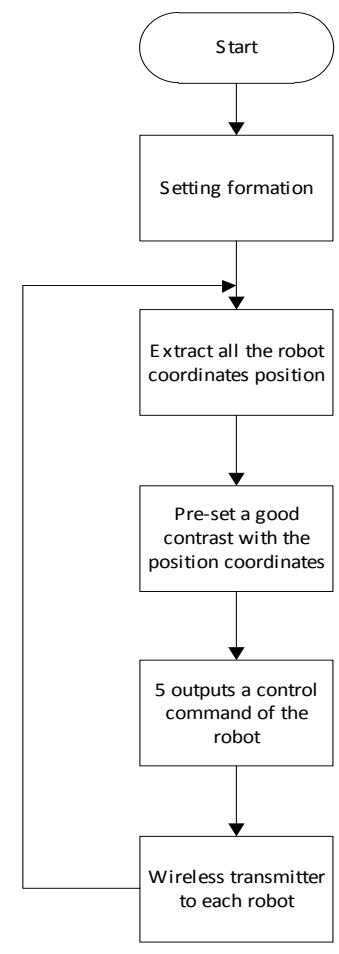

Fig. (12). Robot formation control flowchart. 


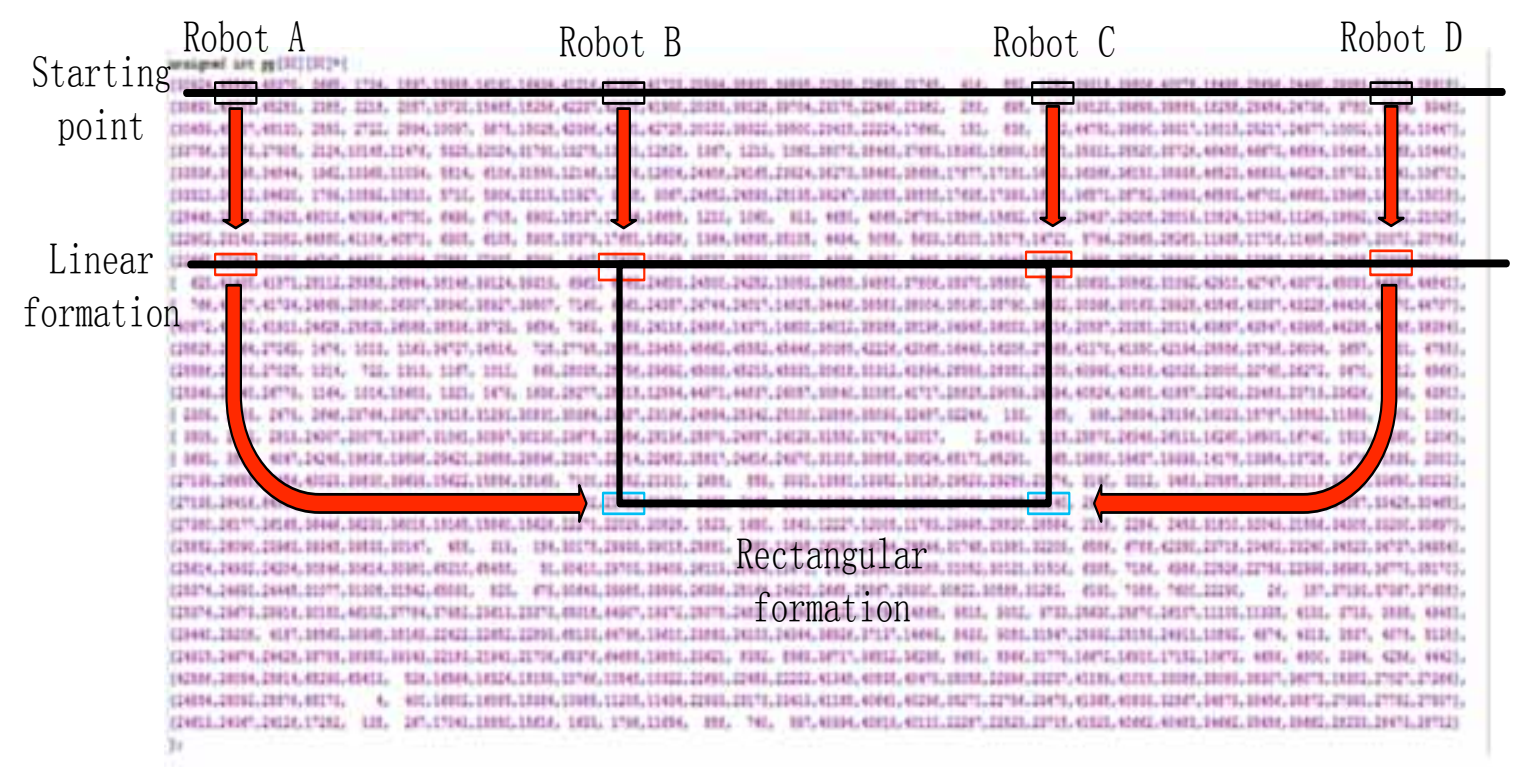

Fig. (13). Figure robot target formations.

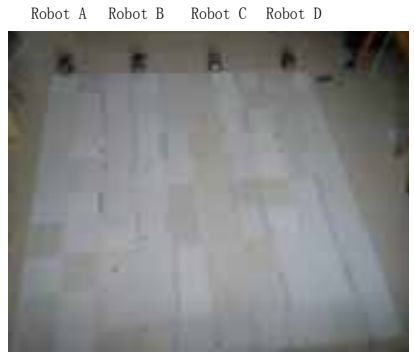

(a)

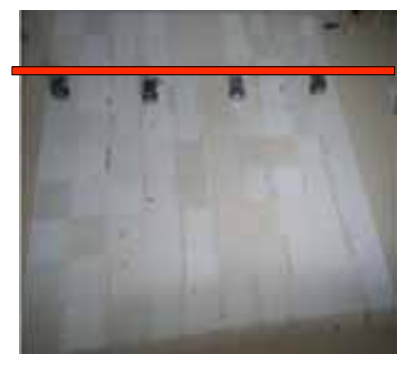

(b)

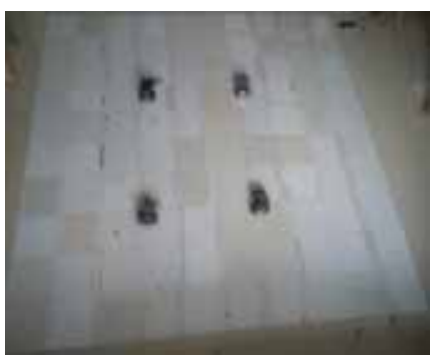

(c)

Fig. (14). Experimental test pattern formation control robot.

Table 1. Control instruction list.

\begin{tabular}{|c|c|}
\hline Command & Operations Performed by Robot A \\
\hline \hline 0x68 & Straight \\
\hline $0 \times 69$ & Retreat \\
\hline $0 \times 70$ & Turn left \\
\hline $0 \times 71$ & Turn right \\
\hline
\end{tabular}

center of the mode of transmitting the start instruction, the robot a, B, C, D will travel to the linear formation as shown in Fig. (13) (A: P [8] [1], B: P [8] [10], C: P [8] [20], D: P [8] [28]), after the destination of each robot go to the control center after the control center to collect data from all of the robot, so that the transmission instruction a, D continue to follow the direction of travel as shown in Fig. (13) to the destination block blue circle (A: P [19] [10], B: P [8] [10], C: P [8] [20], D: P [19] [20]), and finally the robot a, B, C, D consisting of a rectangular formation. Robots A, B, C, D from the position shown in Fig. (6-2) of the kind shown in Fig. (1). The straight line formation robots A, B, C, D is formed as shown in Fig. (2). Fig. (6-3) physical robots A, B rectangular formation $\mathrm{C}, \mathrm{D}$ physical form shown in Fig. (3) Fig. (6-4).

The robot can be seen from Fig. (14a,b,c,d) consisting of straight and rectangular formation, it is not very accurate, the error present in the experiment are the following:

(1) Of the robot in the process of detection of RFID, since the running speed is too fast, no card can be read out completely, or the robot is between the two RFID, the reader cannot read the card, resulting in the robot track.

(2) When the robot reaches the destination, due to inertia, the robot moves a short distance.

(3) Radio transmission process may be delayed. The start time of each robot is difficult to reach consensus.

(4) Wireless transmission process will be packet loss. The robot cannot do anything in accordance with a preset program.

\section{CONCLUSION}

Control multiple robots are a very complex but a study of great significance in life we need more robots to create 
wealth and convenience. Nowadays, with the development of social needs and technological progress is no longer a separate control of each robot, but the group operating the robot, the robot in the system work together to complete a variety of activities. This design is based on a status qua for the indoor multi-robot formation control of wireless sensor network research methods. Through the formation of ZigBee network, a wireless communications platform to build a robot and the control center, combined with electronic compass and RFID radio frequency technology to achieve positioning morphology evaluation of the robot, the robot gives control algorithm, and ultimately the formation control of multiple robots.

\section{CONFLICT OF INTEREST}

The authors confirm that this article content has no conflict of interest.

\section{ACKNOWLEDGMENTS}

The authors are highly thankful for the Guangxi Natural Science Foundation (ID: 2013GXNSFBA019282), Research Program of science at Universities of Guang Xi Autonomous Region (ID: ZD2014112, 2013YB205), This research was financially supported by the project of outstanding young teachers' training in higher education institutions of Guangxi, Guangxi Colleges and Universities Key Laboratory Breeding Base of System Control and Information Processing.

\section{REFERENCES}

D. Ren, and G. Lu, "Reflections on the formation control," Control and Decision, vol. 6, pp. 602-603, 2005.
[2] H. Sandro, A. Javier, and B. Andreas, "Multi-Robot formation control via a real-time drawing interface", Field and Service Robotics, vol. 92, pp. 175-189, 2014.

[3] T. P. Nascimento, A. Gustavo, S. Conceição, "A generic framework for multi-robot formation control", RoboCup 2011: Robot Soccer World Cup XV, vol. 7416, pp. 294-305, 2012.

[4] Y. Chen, and Y. Wang. "A generalized framework of dynamic role assignment for robot formation control", International Journal of Control, Automation and Systems, vol. 8, no. 6, pp. 1288-1295, 2010.

[5] G. Zuo, J. Han, and G. Han, "Multi-robot formation control using reinforcement learning method", Advances in Swarm Intelligence, vol. 6145, pp. 667-674, 2010.

[6] T. Balch, R.C. Arkin, "Behavior-based formation control formultirobot teams", IEEE Transactions on Robotics and Automation, vol. 6, pp. 926-939, 1998.

[7] J. Peng, X. Li, and Z. Qin, "Swarm-robot system based on wireless sensor network", Journal of Digital Information Management, vol. 10, no. 5, pp. 277-283, 2012.

[8] M. Yutian, D. Lihua, F. Hao, C. Jie, "Flocking of multi-robot systems with connectivity maintenance on directed graphs," Journal of Systems Engineering and Electronics, vol. 25, no. 3, pp.470-482, 2014.

[9] Y. Cai, Z. Tang and C. Zhao, "New layered SOA-based architecture for multi-robots cooperative online SLAM," Chinese Journal of Electronics, vol. 23, no. 1, pp. 25-30, 2014.

[10] G. Antonelli, F. Arrichiello, and S. Chiaverini, "Flocking for multirobot systems via the null-space-based behavioral control," Swarm Intelligence, vol. 4, pp. 37-56, 2010.

[11] H. Shan, H. Cai, and D. Tan, "For assembling multi-robot cooperation and coordination system," Robot, vol. 21, no. 1, pp. 50-56, 1999.

[12] J. Wang, "Multi-robot Formation Control Method," Liaoning: Shenyang University of Technology, China, 2009.

(C) Jiansheng Peng; Licensee Bentham Open.

This is an open access article licensed under the terms of the Creative Commons Attribution Non-Commercial License (http://creativecommons.org/licenses/by-nc/3.0/) which permits unrestricted, non-commercial use, distribution and reproduction in any medium, provided the work is properly cited. 